ARTICLE

https://doi.org/10.1057/s41599-020-0389-4

\title{
Online customer behavior: perceptions regarding the types of risks incurred through online purchases
}

Tatiana Marceda Bach (10 1, Wesley Vieira da Silva ${ }^{2}$, Adriano Mendonça Souza ${ }^{2}$, Claudineia Kudlawicz-Franco ${ }^{3}$ \& Claudimar Pereira da Veiga (i) ${ }^{4 \star}$

\begin{abstract}
ABASTRACT Deciding to make online purchases can be risky and retailers have an opportunity to influence the consumer's decision-making process. The aim of this article is to gauge the impact of different types of risks on trust and decision making with regard to online purchases. We conducted a survey with adaptations to three theoretical scales. To analyze the impact of risk on the variables of trust and decision making, a confirmatory factor analysis was performed, and to clarify the relationships between these constructs, a structural equation model was prepared. A qualitative $(n=13)$ and quantitative study were conducted with primary data $(n=328)$ collected by means of a structured questionnaire using a sample of a group of consumers who reside in the south of Brazil. The article makes four main contributions to the field: (i) it identifies the influence of three latent constructs that might affect online purchase behavior; (ii) it gauges the risks associated with the latent construct of trust and the adaptation of scales of perceived risk and decision making; (iii) it highlights the need to reassess the strategies adopted by companies that sell online to reduce risks and consequently increase trust in decision making; and (iv) it evaluates the demographic variables that have a significant moderating effect on the relationships of the constructs of trust and decision making during the purchase process.
\end{abstract}

\footnotetext{
${ }^{1}$ Centro Universitário Univel (UNIVEL), Cascavel, Brazil. ${ }^{2}$ Universidade Federal de Santa Maria (UFSM), Santa Maria, Brazil. ${ }^{3}$ Pontifícia Universidade Católica do Paraná (PUCPR), Curitiba, Brazil. ${ }^{4}$ School of Business Administration, Universidade Federal do Paraná (UFPR), Curitiba, Brazil. *email: claudimar.

veiga@gmail.com
} 


\section{Introduction}

$\mathrm{n}$ the current economic scenario, with the growth of online commercial retail transactions, the recent literature has highlighted the distributed intelligence emerging from all human and technological agents interacting on the internet (Heylighen and Lenartowicz, 2017). In recent decades, the retail sector has undergone a huge digital transformation (Hagberg et al., 2017), such as the integration of new digital technologies (Petit et al., 2019), digital business models (Xu and Koivumäki, 2019), including platform-based multi-sided market places (Hänninen et al., 2019), access to information, a global vision, and changes in computation and mobile shopping (Faulds et al., 2018). All of these digital transformations have led to changes in people's purchase behavior and, consequently, that of the consumer.

Traditional economic theory claims that consumers are rational and systematically seek and analyze information in the market prior to making a purchase. However, in traditional economic theory, it is impossible to obtain and analyze all the information on the whole market before making a decision (Balakrishnan et al., 2019; Khalil et al., 2019). In the digital economy, time, credibility, and attention, rather than information, are scarce. Making a secure purchase reduces cognitive dissonance, the distance between what is expected and what is received. The greater this distance (in situations where what is "received" is worse than what is "expected") the more unsatisfied the consumer will be with his purchase (Festinger, 1957; Liao, 2017; Keng and Liao, 2009). The more complex the product, and the more expensive and important it is to the customer, the more he will search online for information on the product and the store.

With the new digital technologies, the consumer's decisionmaking process is described as a continuous and interactive activity, requiring retailers to adopt a more holistic mentality and concentrate on influencing the process rather than concentrating exclusively on the result of the consumer's decision (Conrado, 2018; Faulds et al., 2018). A critical factor in the decision-making process in the digital environment is credibility, which enables the achievement of a higher conversion rate. Credibility can be gained in a number of ways to make a company that theoretically only exists in bytes tangible. It is necessary to make the company concrete, palpable, and tangible. Furthermore, after making it tangible, it is necessary to show consumers that a company that conducts transactions online is honest and reliable (Cetina et al., 2012; Faulds et al., 2018; Conrado, 2018).

The internet has led to a significant increase in the number of transactions and options for products and services (Zhuang et al., 2018). In this respect, online commercial transactions have grown enormously in recent years (Raluca, 2018), despite uncertainty regarding the quality of products due to the lack of a previous experience. This is because online transactions mean more comfort and savings for consumers who make decisions to buy through this channel (Kim and Krishnan, 2015; Conrado, 2018). Online purchases are not free of different kinds of risk, mainly due to the complexity and diversity of information involved in these transactions.

The volume of information available on the internet is equivalent to approximately one septillion bytes of information, which are interconnected worldwide, according to the leading information management company in the world, EMC (Machado, 2014). The amount of online data in virtual retail does not guarantee their quality, nor do they reflect how serious companies are with regard to selling their products on the internet. Furthermore, there is a risk of not receiving products, receiving inadequate products or services and cognitive dissonance (Festinger, 1957; Novak et al., 2000; Keng and Liao, 2009; Kim and Krishnan, 2015).
The consumer's perceived risk in decision making is associated with elements related to previous experience and past purchases. This perceived risk diminishes as the consumer makes more purchases and undergoes more similar shopping experiences (Liebermann and Stashevsky, 2002). Although having made a purchase online can help to reduce risks, each new purchase remains unique and singular (Cunningham et al., 2005). The role of marketing, which is now digital, is to increase the value perceived by the consumer, especially regarding purchases and value generation in the online environment. The challenge for retailers nowadays is to minimize risks for consumers in online shopping.

The literature includes a number of studies that analyze different aspects of risk in different countries. Some authors have investigated the behavior of acceptance and use of online shopping in Thailand, highlighting perceived risk (Driediger and Bhatiasevi, 2019), risk reduction strategies in online purchases in Greece (Vos et al., 2014), research on the influence of perceived risk in consumers' online purchasing decisions (Hong and Yi, 2012), and risk with regard to subjective representations in purchase decisions (Costa, 2007). Others have evaluated the influence of demographic aspects in risk perception (Maceira et al., 2011), risk regarding the security and privacy of individual information (Korgaonkar and Wolin, 1999), the influence of risk and trust in the purchase of stocks and shares and decision making in corporate software purchases (Costa, 2007), to name a few. Recent efforts have highlighted the influence of psychological risk and social risk on product purchase intention (Swiegers, 2018) and the influence of financial risk on purchase decision in the profile of women who purchase luxury brand products online (Wahab et al., 2019).

In Brazil, Costa (2007) investigated the influence of trust on the degree of perceived risk in the purchase of shares. No studies were identified in the Web of Science and Scopus databases concerning the joint influence of three latent constructs that might affect online consumer behavior: (i) types of risk; (ii) trust; and (iii) decision making. To address this gap, the research question to be answered is: What is the impact of the different types of risk on trust and decision making in online purchases? Although a number of studies have been conducted on the different types of risks associated with online purchases, little is known of the nature of these risks in the Brazilian context. In this sense, it is important to consider the willingness of consumers to purchase online by mapping which kinds of risk are considered more prominent and which can affect their trust and decisions.

The empirical relevance of this article lies in its applicability to different areas of business that provide individuals with options for online shopping. It also presents firms with the consumer's viewpoint when it comes to deciding on a product and/or service. This study helps to understand how purchase decisions are associated with trust or motivation when consumers opt to purchase a product or service (Mitchell, 1999).

This article differs from previous works by including a multigroup analysis, as the articles referenced in this study made no suggestions about dividing the sample into groups to evaluate the mediating effects of demographic variables. The results of the multigroup analysis, with demographic characteristics, will be divided into groups to investigate whether the specific categories of each of them have an effect on the latent variables of trust and decision making in online purchases.

The study is structured into four sections after this introduction. In the second section, the theoretical background regarding perceived risk, trust and decision making is presented. In the third section, the methodological procedures are described. In the fourth section, the analyses and results are presented, followed by the final considerations in the last section. 


\section{Perceived risk, trust, and decision making}

The measurement of risk perception was first investigated by Cunningham (1967). Later, new themes related to perceived risk in decision making were added, as well as the identification of the decision-making process and its influence on consumers. The authors involved in this research included Dowling (1986), Dowling and Staelin (1994), Mitchell (1991), Mitchell (1990), Das and Teng (2004), Loomes and Mehta (2007), and Lin (2008). From these studies, perceived risk came to be viewed as a multidimensional construct, made up of dimensions related to physical loss, financial loss, psychological loss, time loss, performance risk (e.g. functional loss) and social or global risk (Roselius, 1971; Jacoby and Kaplan, 1972; Mitchell, 1999). A caveat added by Bauer (1960) is that it is difficult to measure the dimensions of risk objectively. This can be overcome by conducting studies on risk perception or subjective risk.

The conceptualization of risk provides clearer information on how perceived risk can affect consumer decision making (Bertea and Zait, 2013), and one of the classic views of the different types of risk considers elements from authors, such as Jacoby and Kaplan (1972) and Mitchell (1999). In accordance with the types of risk: (i) global risk or physical loss involves more wide-ranging aspects of risk, consisting of different varieties of risk forming a certain situation (Jacoby and Kaplan, 1972); related to risk incurred in the value of the product, (ii) financial risk is generally linked to high aggregate value products, with a greater risk of financial loss (Mitchell, 1999); (iii) psychological risk considers the motivations that make the decision maker feel comfortable with running a certain risk; (iv) negative risk has to do with not making a good choice, which can cause stress, anxiety and/or fear of making a new purchase (Mitchell, 1999); (v) time risk has to do with the time to make a purchase and the time used if there is a defect or repairs to be made; and (vi) performance risk is related to the product's attributes and whether it functions properly, i.e., its quality (Mitchell, 1999).

Similar kinds of products can pose similar risks, and global risk may be linked to the other types of risk: (i) financial; (ii) psychological; and (iii) physical and social. Furthermore, there may be a behavior pattern concerning the types of risks and products. Thus, clothing items may pose a greater psychological risk, and electronic products may pose a greater financial and performance risk (Jacoby and Kaplan, 1972). There may also be variations in perceived risk depending on the consumer's degree of involvement in the purchase decision, because when he perceives a greater risk, his degree of involvement is more intense (Bertea and Zait, 2013).

Although previous online purchases can help to reduce risks, which diminish as the consumer gains experience (Liebermann and Stashevsky, 2002), each purchase through this medium remains unique (Cunningham et al., 2005). This is because when it comes to the internet, the risks involved in online shopping are still greater than in traditional establishments (Maceira et al., 2011). In online purchases, Korgaonkar and Wolin (1999) warn of risks related to security and the privacy of individual information. Moreover, other factors may be involved in the decision to run risks, such as human behavior (Meertens and Lion, 2008), external elements that offer some kind of psychological consolation (Costa, 2007), and the way products purchased online are delivered (e.g. mail, courier, drone, motorcycle, or direct collection from the store) (Cunningham et al., 2005).

Trust is closely linked to risk perception and decision making because perceived risk is an antecedent of trust (Costa, 2011) and with this risk reduced, trust increases when it comes to purchasing a product and/or service, supporting the purchase decision. In this context, Costa (2011) highlights that trust is closely related to vulnerability, expectations, and the individual's control.
Furthermore, it is an important element that can aid decision making, considering the uncertain future and inherent risk.

In the literature, although there are many studies related to risk and trust, this association could be better clarified (Das and Teng, 2004) by considering its relationship with decision making. The decision process involving risk can be explained by six models: (i) the rational; (ii) bounded rationality; (iii) political; (iv) logical incrementalism; (v) the subjective; and (vi) the garbage can model (Audy, 2001; Miller et al., 2004). In the rational model, planning and mental activities are the bases for decision making, mainly because the individual analyzes them carefully before deciding whether he is able to foresee the consequences (Morgan and Hunt, 1995; Miller et al., 2004; Costa, 2011). In the bounded rationality model, it is impossible for the individual to have the knowledge to capture all the information that forms the basis for decisions because doing so depends on his human cognition and how he interprets and attributes relationships to its meanings (Miller et al., 2004). The third model, the political one, uses power, influence and authority in decision making and considers the need to exchange and negotiate with other individuals. Thus, external elements are incorporated into the decision process and risk analysis (Miller et al., 2004).

The fourth, incremental, model considers informal and subjective aspects in decision making. In this model, relationships and meanings are built with experience, considering aspects associated with the intellect and mental relationships (Weick, 1995). In the fifth model, concerning subjectivity, the decision maker can choose, based on beliefs, emotions, and feelings, a considerable volume of information and situations that he can find. It also suggests that the decision maker may not be in a position to make the same decision in similar contexts, as the perceived risk depends on the fear and disappointments that he has already experienced (Weick, 1995). The sixth model, the garbage can, views decision making as not being a harmonious process. Choices cease to follow an ordered pattern and are linked to a process in which decisions are made based on problems and other opportunities (Cohen et al., 1972).

The consumer's choice regarding whether or not to make a purchase does not intrinsically consist of his ability to attribute rules, consider previous facts, his interpretation of the facts and future expectations, because decisions and perceptions differ from one individual to another. Consumers often make comparisons between past experiences using a mental model imbued with meanings (Costa, 2011).

The framework for the adoption of a determined form of behavior in decision making is rational action theory, which clusters elements from decision models to explain how relationships, attitudes, expectations, norms, intentions, and beliefs are established (Karahanna et al., 1999). Furthermore, it is supported by personal interests and social influences, mainly because the theory assumes that an individual's behavior is motivated by the personal and social benefits he desires (Karahanna et al., 1999).

\section{Methodological procedures}

This article uses a quantitative-descriptive approach and gauges the impact of different types of risk on the consumer's trust in decisions to make online purchases. The data collection procedures included a survey, complemented by statistical methods (Hair et al., 2009).

To achieve the proposed goal, it was necessary to adapt the scale of Cunningham et al. (2005) and Hor-Meyll (2004), who assessed the risks incurred in the recognized latent constructs, such as: (i) general losses; (ii) financial losses; (iii) performance losses; (iv) psychological losses; and (v) time losses. Moreover, the latent constructs of trust and decision making were measured 


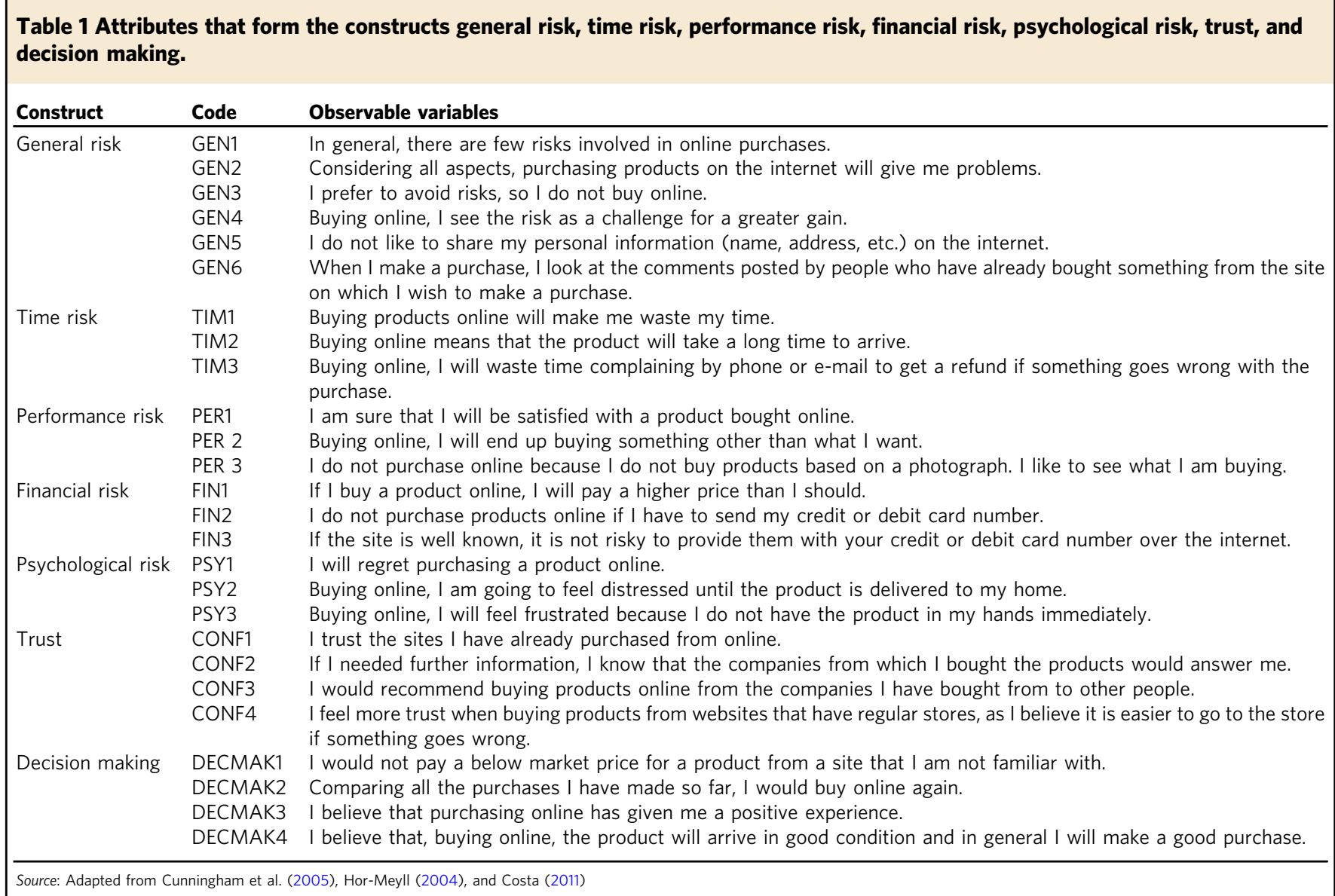

using the scale of Costa (2011). To measure the performance of the constructs of (i) types of perceived risk; (ii) trust; and (iii) decision making, a structured questionnaire comprising 35 observed variables was adapted, in which each respondent marked the extent to which he agreed on a 5-point Likert scale, ranging from 1 "I totally disagree" to 5 "I totally agree". The structured questionnaire was intended to identify the impact of the latent constructs, such as: (i) global risk or physical loss of the product; (ii) financial risk; (iii) psychological risk; (iv) time risk; (v) performance risk; and (vi) trust in online purchases and decision making. At the end of the questionnaire, a space was made available for comments on problems experienced in past purchases.

Furthermore, an attempt was made to identify problems with the research tool through a pre-test. At first, face validation or apparent validation was performed. According to Urbina (2007), this has to do with the concepts used in formulating the variables, with a view to gauging whether the language is in accordance with what is intended to be measured. In other words, it has to do with whether the superficial appearance of what is being measured. It should be understandable to an examiner or any individual familiar with the subject in question. The attributes that form each of the constructs in question are shown in Table 1.

Prior to the data collection, a (qualitative) pre-test was conducted with 13 consumers to identify their perception of the formulation of the questionnaire. After making suggested adjustments, the questionnaire was applied to a sample of consumers who reside in the south of Brazil and decided to purchase products and/or services online. The region where the research was conducted was chosen due to the high purchase power of the consumers and because of its economic importance to the country.
The sample was selected using non-probabilistic snowball sampling. The analysis unit consisted of consumers who had decided to purchase products and/or services online. The questionnaire was applied by e-mail from March to June 2018 to consumers who had already made online purchases.

We used the free software $\mathrm{G}^{\star}$ Power 3.19.2 (http://www.gpower. hhu.de/en.html) to estimate the minimum size of the sample to be collected, taking into account the number of predictors of the dependent variable, the test power and effect size $\left(f^{2}\right)$. According to Hair et al. (2014), test power equal to 0.80 is recommended and an effect size $\left(f^{2}\right)$ equal to 0.15 , while the number of predictors observed in the model for this study is equal to 2 . This results in a minimum sample recommended by the software of 107 respondents. Hair et al. (2014) highlight that PLS-SEM does not require a minimum number of respondents. In this case, the higher the number of respondents, the greater the consistency of estimations based on this model will be. Thus, a total of 422 questionnaires were collected. Those that were incomplete were excluded, resulting in 328 valid questionnaires. The operational definition of the latent constructs and their theoretical bases are presented in Table 2.

To draft the 17 hypotheses, research related to perceived risk, trust, and decision making served as a framework. For this purpose, Mitchell (1995) highlights that perceived risk is a precedent for trust because individuals, when perceiving a lesser risk in their purchase, may feel more comfortable when confirming it. Kim et al. (2008) argue that trust, in certain contexts, can minimize or maximize perceived risk. Consequently, Das and Teng (2004) point out the need for further research to clarify the relationship between risk and the trust it entails. In turn, Costa (2011) argues that through past experiences an individual will decide whether to 
Table 2 Operationalization of the research construct with general risk, time risk, performance risk, financial risk, psychological risk, trust and decision making based on literature.

\section{Latent constructs Operationalization of the variables}

General risk

Time risk

Performance risk

Financial risk

Psychological risk

Trust

Decision making be made customer satisfaction
General aspects related to risk; different independent varieties of risk form the situation in which the decision maker is involved

Time spent on making the purchase and time spent if there is a defect or repairs to

Attributes of the product or service related to it functioning well, resulting in

Products with high added value mean a greater financial risk or greater loss

Reasons why decision makers run a certain risk to make a purchase. When negative, this can lead to stress anxiety and fear of making a new purchase The individual's vulnerability, expectations and control

Capacity to attribute rules, consider previous facts and interpret facts and expectations

\section{Source}

Jacoby and Kaplan (1972), Cunningham et al. (2005), and Hor-Meyll (2004)

Mitchell (1999), Cunningham et al. (2005), and Hor-Meyll (2004)

Mitchell (1999), Cunningham et al. (2005), and Hor-Meyll (2004)

Mitchell (1999), Cunningham et al. (2005), and Hor-Meyll (2004)

Mitchell (1999), Cunningham et al. (2005),

and Hor-Meyll (2004)

Costa (2011)

Costa (2011)

\section{Table 3 Research hypotheses for each construct.}

$\mathrm{H}_{1} \quad$ General risk affects trust in online purchases

$\mathrm{H}_{2} \quad$ Time risk affects trust in online purchases

$\mathrm{H}_{3} \quad$ Performance risk affects trust in online purchases

$\mathrm{H}_{4} \quad$ Financial risk affects trust in online purchases

$\mathrm{H}_{5} \quad$ Psychological risk affects trust in online purchases

$\mathrm{H}_{6} \quad$ General risk affects decision making in online purchases

$\mathrm{H}_{7} \quad$ Time risk affects decision making in online purchases

$\mathrm{H}_{8} \quad$ Performance risk affects decision making in online purchases

$\mathrm{H}_{9} \quad$ Financial risk affects decision making in online purchases

$\mathrm{H}_{10} \quad$ Psychological risk affects decision making in online purchases

$\mathrm{H}_{11} \quad$ Trust affects decision making in online purchases

$\mathrm{H}_{12}$ The socio-demographic characteristic of respondents' gender has a significant effect on trust

$\mathrm{H}_{13}$ The socio-demographic characteristic of respondents' gender has a significant effect on decisions to make online purchases

$\mathrm{H}_{14}$ The socio-demographic characteristic of respondents' age has a significant effect on trust

$\mathrm{H}_{15}$ The socio-demographic characteristics of respondents' age has a significant effect on decision making regarding online purchases

$\mathrm{H}_{16}$ The socio-demographic characteristic of respondents' level of education has a significant effect on trust

$\mathrm{H}_{17}$ The socio-demographic characteristic of respondents' level of education has a significant effect on decision making regarding online purchases

Table 4 Acceptable values in the literature for structural equation modeling for convergent validity, composite reliability, and internal consistency reliability.

Validity test

AVE

CR

Cronbach's alpha

\section{Purpose}

Convergent validity

Composite reliability of the model

Internal consistency reliability

\section{Acceptable limit}

AVE $>0.50$

$C R>0.70$

$C A>0.70$ or $C A>0.60$

\section{Authors}

Henseler et al. (2009)

Hair et al. (2014)

Hair et al. (2014,

2009); Malhotra (2001)

Source: Adapted from Hair et al. (2014)

run a risk with a certain purchase, as each individual is involved in a mental process imbued with meanings and associations. These factors will be taken into consideration when opting to take a risk. These studies support the proposition of the hypotheses that guide this study, as shown in Table 3 .

To analyze the impact of risks on the variables that represent trust and decision making, a confirmatory factor analysis (CFA) was conducted to test to what extent the variables that were measured represent a construct, considering in this case the theoretical relationships that have already been substantiated. Now it was necessary to test them empirically (Hair et al., 2009). Structural equation modeling (SEM) was then used with a goodness of fit estimation of partial least squares (PLS). The application of this model consists of calculating the correlations between (latent) constructs and their observed variables (indicators), followed by linear regressions to test the impact between constructs. This methodology is used in situations in which the data are configured as not normal, the samples are small and indicators that structure a construct are used (Hair et al., 2014).

Following the assumptions of adaptation of scale, an exploratory stage was used to gauge whether the latent constructs were reflected in their observed variables, as well as the relationship between the constructs. Following this stage, the study progressed to a confirmatory analysis model of the data.

With a view to testing the validity of the confirmatory model, average variance extracted (AVE) tests were performed, along with composite reliability (CR) and Cronbach's alpha. The reference values for each of these tests are shown in Table 4. 


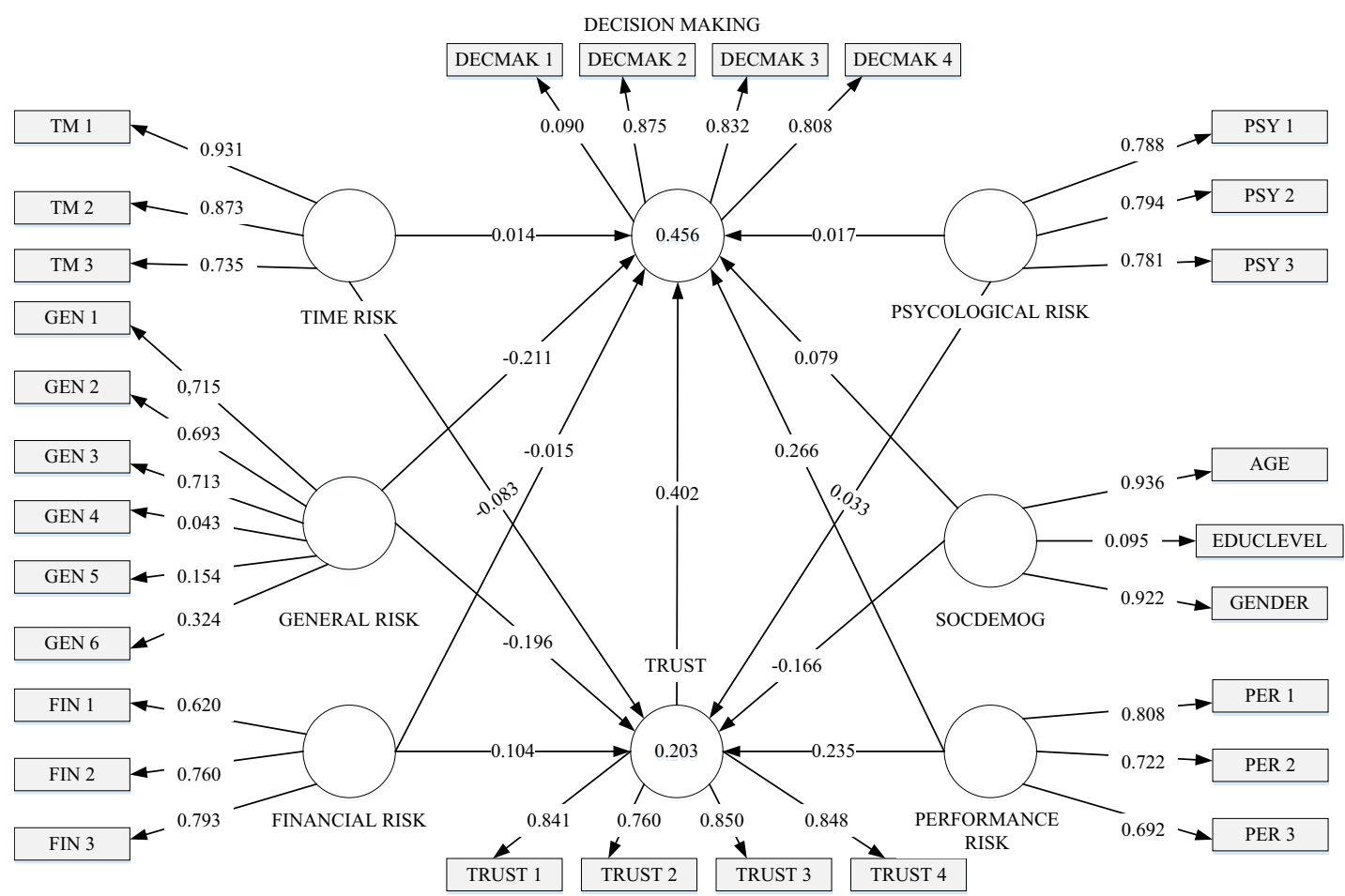

Fig. 1 First round of the proposed model for performing the CFA for the constructs of general risk, time risk, performance risk, financial risk, psychological risk, trust, decision making, and demographics.

The values obtained through these indicators confirm the validity of the study. Thus, the recommendations of Hair et al. (2009) were followed to gain convergent and discriminant validity. Convergent validity, evaluated by the values of the factor loadings, the AVEs, CR, and Cronbach's alpha, considers that the items in a construct should converge with a high proportion of variance in common. It is estimated through the factor loadings when these are high for a factor. Thus, they indicate that they converge to a common point. When evaluated by the AVE of a set of constructs, convergent validity indicates convergence if the value of the AVE is higher than 0.5. This also occurs if the CR value is higher than 0.7 . When verified by reliability (Cronbach's alpha), it measures the internal consistency between the constructs, indicating that the measurements represent the same latent construct. Discriminant validity evaluates how much a construct differs from the others. Thus, the higher the discriminant validity, the more evidence there is that a construct is unique and captures information that the others do not. This validity is measured when the values of the AVE for each factor are higher than the estimates of the squared correlations between constructs associated with the factor.

The bootstrapping and blindfolding methods were used. Bootstrapping is used in PLS to obtain the confidence intervals in the coefficients. In this study, the resampling procedure was employed for 2000 samples (Morelatto, 2010). Meanwhile, the blindfolding model evaluates the goodness of fit indicators of the model through the predictive validity $\left(Q^{2}\right)$ and effect size $\left(f^{2}\right)$ values. When measured by the predictive validity $\left(Q^{2}\right)$, it evaluates how close the model comes to the theoretically proposed original. When measured by the effect size $\left(f^{2}\right)$ indicator, it measures the utility of the construct for the fit of the model (Hair et al., 2014).

\section{Presentation and analysis of the data}

To test the reliability of the model, the values of the average variances extracted (AVE), CR, the coefficient of determination
$\left(R^{2}\right)$ and Cronbach's alpha were generated. Likewise, the bootstrapping and Student's $t$ test were generated and the evaluation of the goodness of fit indicators of the model through blindfolding for the predictive validity $\left(Q^{2}\right)$ and effect size $\left(f^{2}\right)$ values. Initially, the descriptive statistics were extracted to verify demographic characteristics of the sample.

An analysis of the data shows that the sample was predominantly male, accounting for $62.5 \%$ of the respondents (205 men). Women made up $37.5 \%$ of the sample (123 respondents). Approximately $46.95 \%$ of the respondents were aged $17-29$, while $33.84 \%$ were in the $30-46$ age group, comprising $\sim 33.84 \%$ of the sample. Those over the age of 47 accounted for around $19.21 \%$ of the sample. Concerning their level of education, 52 respondents (15.9\%) had a university degree and were male. Ninety respondents, including both men and women (12.2\% and $15.2 \%$, respectively), had completed a specialization course.

Regarding how frequently the respondents make online purchases, 20 have made at least one purchase, corresponding to $6.1 \%, 125$ have made more than one online purchase, corresponding to $38.1 \%$, and 183 respondents, the vast majority, said that they constantly make online purchases, accounting for $55.8 \%$. Based on the constructs defined in the theoretical framework of this study, all the items were evaluated as reflexive indicators (Hair et al., 2009; Mackenzie et al., 2005). In this context, the CFA was estimated with all the constructs connected to one another, as in Brown (2006). The model was estimated with SmartPLS 3.0 software (Ringle et al., 2015), using the factor weighting scheme.

The results of the CFA estimated with the aid of SmartPLS software for each risk attribute (e.g. time, performance, financial, psychological, and general) and the relationship with trust in decision making can be seen in Fig. 1.

In the initial model, some values of the AVE were lower than 0.5. Considering that this stage is exploratory, it can be said that the construct of general risk, decision making, and level of education of the demographic data construct are not reflected by the total set of indicators (observations) that formed them. 
Table 5 Values of the goodness of fit of the first model for the CFA for the constructs of general risk, time risk, performance risk, financial risk, psychological risk, trust, decision making, and demographics.

\begin{tabular}{|c|c|c|c|c|}
\hline Latent constructs & AVE & Composite reliability (CR) & Adjusted $R^{2}$ & Cronbach's alpha \\
\hline General risk & 0.272 & 0.615 & - & 0.398 \\
\hline Performance risk & 0.549 & 0.784 & - & 0.604 \\
\hline Psychological risk & 0.620 & 0.830 & & 0.709 \\
\hline Trust & 0.682 & 0.896 & 0.188 & 0.846 \\
\hline Decision making & 0.530 & 0.783 & 0.444 & 0.656 \\
\hline Demographics: age, gender, and schooling & 0.578 & - & - & - \\
\hline
\end{tabular}

\begin{tabular}{|c|c|c|c|}
\hline Latent constructs & AVE & $\begin{array}{l}\text { Composite } \\
\text { reliability (CR) }\end{array}$ & Cronbach's alpha \\
\hline General risk & 0.578 & 0.804 & 0.642 \\
\hline Time risk & 0.732 & 0.890 & 0.814 \\
\hline Performance risk & 0.548 & 0.784 & 0.604 \\
\hline Financial risk & 0.530 & 0.770 & 0.599 \\
\hline Psychological risk & 0.620 & 0.830 & 0.709 \\
\hline Trust & 0.682 & 0.896 & 0.846 \\
\hline Decision making & 0.704 & 0.877 & 0.790 \\
\hline $\begin{array}{l}\text { Demographics: age } \\
\text { and gender }\end{array}$ & 0.917 & - & - \\
\hline
\end{tabular}

Source: Adapted from Malhotra (2001), Hair et al. (2009) and data research

The criterion commonly used for analysis in SmartPLS is that of Fornell and Larcer, which suggests that AVE values should be higher than 0.50 (AVE > 0.50) (Henseler et al., 2009) and that this measurement should be considered as a criterion for the reliability of the model. The CR test is also used, with an estimated value for general risk equal to 0.615 being found, which is lower than the specification level of 0.7 .

Table 5 presents the estimated values of the confirmatory factor analysis (CFA) for the goodness of fit of the first model.

The AVE values indicate that the observed variables that form the latent variables of trust, decision making, performance risk, financial risk, psychological risk, and time risk are explained by the variables that form them, as shown by the AVE value higher than 0.50 proposed by Henseler et al. (2009).

As the value of some items of the general risk construct was not higher than 0.50 (AVE > 0.50), it was necessary to make adjustments to the model. Likewise, the $\mathrm{CR}$ and Cronbach's alpha values were lower than the expected limit. The lowest accepted limit for Cronbach's alpha, which measures the degree of reliability of the model, is 0.70 . However, in exploratory studies, its acceptable value is reduced to 0.60 (Hair et al., 2009; Malhotra, 2001). CR, according to Hair et al. (2014), is acceptable when its index is higher than $0.70(\mathrm{CR}>0.70)$. However, for characteristic PLS-PM studies, the measurements of CR and AVE are the most suitable (Hair et al., 2009).

Consequently, the adjustment of the model resulted in the exclusion of five items from the scales (DECMAK1, EDUCLEVEL and GEN4, GEN5, GEN6), which had lower than expected factor loadings. Therefore, Hypotheses 16 and 17, respectively, were excluded, and the model was prepared again (see Fig. 2), containing the constructs explained by the variables $($ AVE $>0.50)$.

Figure 2 shows the exclusion of some items from the construct due to their factor loadings being lower than 0.50. It should be highlighted that only items FIN1 and PER3 had factor loadings lower than the reference value of 0.70. To complement Fig. 2, Table 6 shows the results of the fit of the second CFA model.

The AVE values were higher than 0.50 (AVE > 0.50), suggesting that the constructs are explained by the variables in the adjusted model. The CR values were higher than the acceptable limit of 0.7 recommended by Hair et al. (2014) in five constructs (trust, decision making, general risk, psychological risk, and time risk). The Cronbach's alpha, which evaluates the internal consistency of the model, was within the acceptable limit for five constructs (alpha $>0.6$ and 0.7). The lowest limit accepted for Cronbach's alpha is 0.7 . However, in exploratory studies, its acceptable value is reduced to 0.6 (Hair et al., 2009; Malhotra, 2001). A Cronbach's alpha coefficient higher than 0.70 means an acceptable degree of consistency (Hair et al., 2009).

The values obtained through these tests indicate the presence of convergent validity, showing that the constructs converge with one another with AVE values higher than 0.5 , CR over 0.7 and Cronbach's alpha higher than 0.6 indicating that the measurements represent the same latent construct. Some lower Cronbach's alpha values do not affect the convergent validity, since two measurements have already been shown to be higher (AVE and CR) (Hair et al., 2014), as the indices were higher and revealed the validity of the variables observed in relation to their latent variables (constructs).

Discriminant validity evaluates to what extent one construct differs from the others. Therefore, the higher the level of discriminant validity, the less evidence there will be that a construct is unique and captures information that the others do not provide. There were signs of this validity using the criterion of Fornell and Larcker (1981), verifying that all the values of the square roots corresponding to each construct (cross loadings) were higher than the correlation among them. To evaluate the significance ( $p$-value) of the proposed relationship of the correlation (measurement model) and regression (structural model), the bootstrapping resampling test was performed for 2000 samples. Values higher than the limit of 1.96 were predominant, indicating that, for these observed variables, the correlations and regressions of the structural model were highly significant. The acceptable value for evaluating the significance of the correlations and regressions is Student's $t$ test $\geq 1.96$ (Hair et al., 2014).

None of the latent variables was found to have factor loadings lower than the critical value of 1.96 , with the minimum value of three items in the scale being preserved. Following adjustments to the formulated model, excluding some items from the financial risk, performance risk, and decision-making constructs, the 


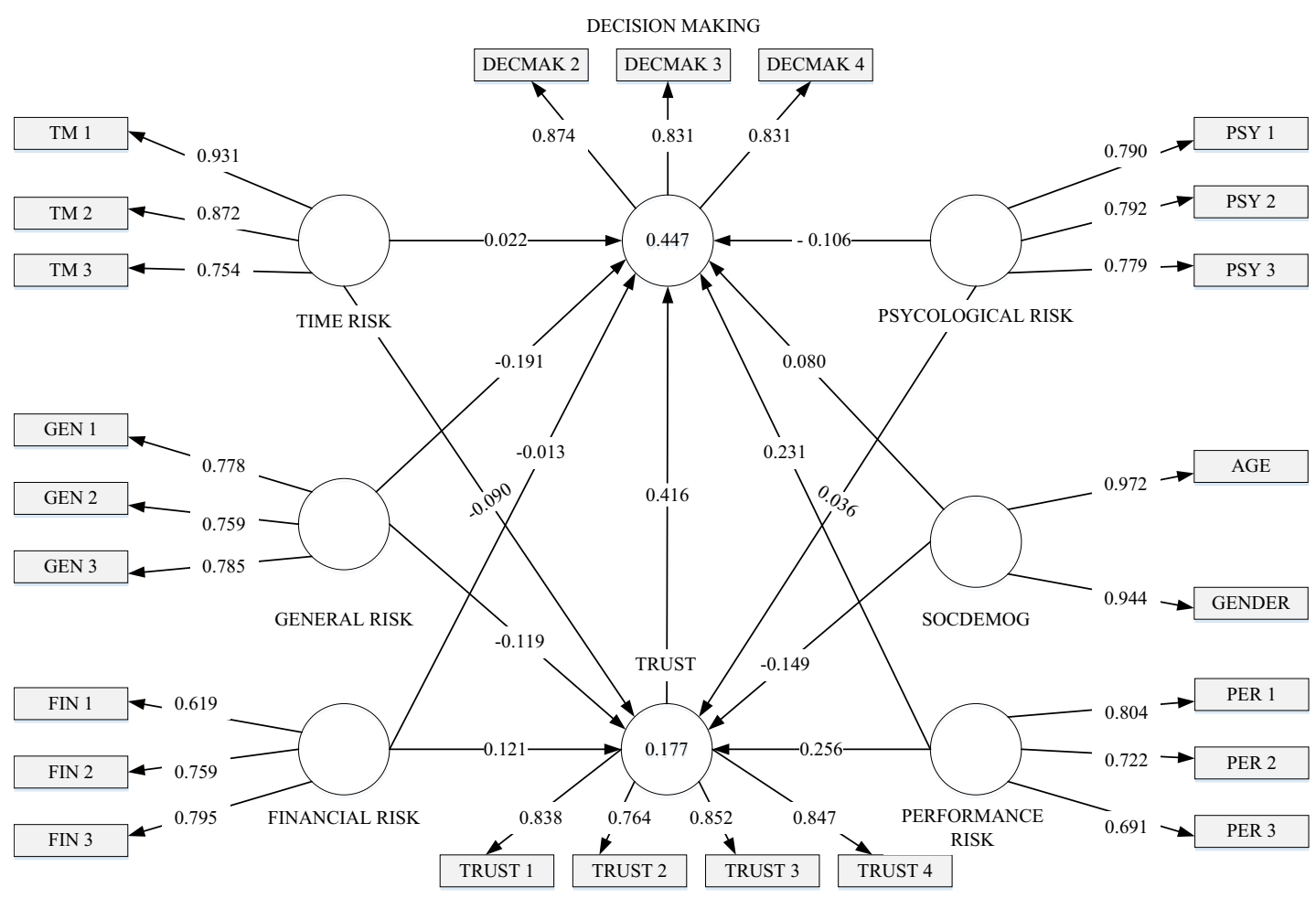

Fig. 2 Second round of the proposed measurement model for the CFA for the constructs of general risk, time risk, performance risk, financial risk, psychological risk, trust, decision making, and demographics.

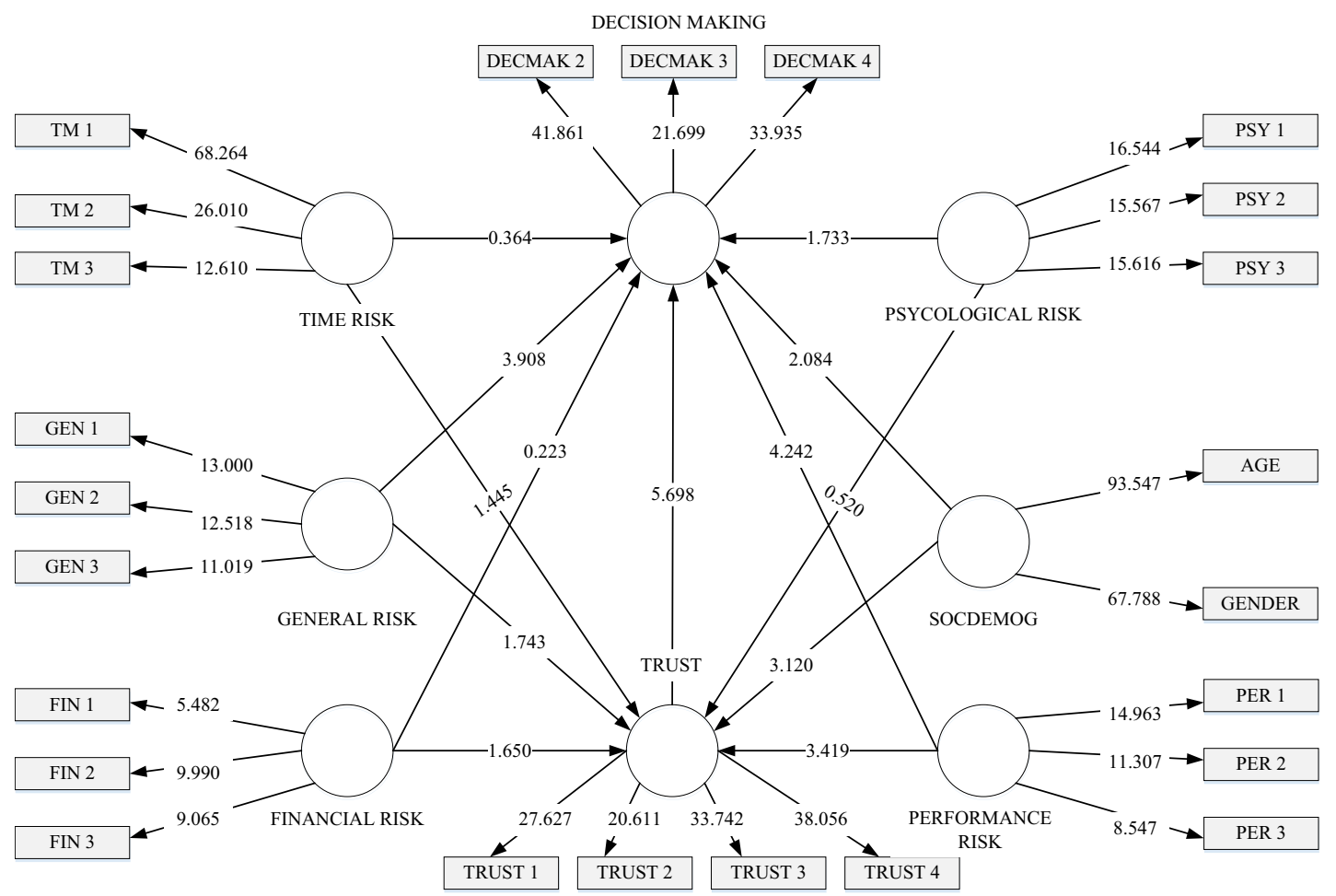

Fig. 3 Structural model after an estimate using bootstrapping for the constructs of general risk, time risk, performance risk, financial risk, psychological risk, trust, decision making, and demographics.

model was estimated again, presenting estimates higher than the specified value. The final confirmatory model with its adjusted structure is shown in Fig. 3. The values of the observable variables containing their respective values obtained using Student's $t$ test are also shown in Fig. 3.
The results presented in Fig. 3 are only indicative of the structure of the variables whose factor load values were above 1.96 , indicating that in the model there are statistically significant relationships. To evaluate which variables are statistically significant, it is necessary to observe the significance values 
Table 7 Result of the impacts of the constructs of general risk, time risk, performance risk, financial risk, and psychological risk on purchasers' trust and reliability.

\begin{tabular}{|c|c|c|c|c|c|}
\hline Relationships & Original sample (0) & Sample mean $(M)$ & $\begin{array}{l}\text { Standard deviation } \\
\text { (STDEV) }\end{array}$ & $\begin{array}{l}\text { T statistics } \\
\text { (|O/STDEV|) }\end{array}$ & $P$ values \\
\hline Financial risk $\rightarrow$ Trust & 0.121 & 0.125 & 0.073 & 1.650 & 0.099 \\
\hline General risk $\rightarrow$ Trust & -0.119 & -0.112 & 0.068 & 1.743 & 0.082 \\
\hline General risk $\rightarrow$ Decision making & -0.191 & -0.187 & 0.049 & 3.908 & 0.000 \\
\hline Performance risk $\rightarrow$ Trust & 0.256 & 0.252 & 0.075 & 3.419 & 0.001 \\
\hline Performance risk $\rightarrow$ Decision making & 0.231 & 0.233 & 0.055 & 4.242 & 0.000 \\
\hline SocDemog $\rightarrow$ Trust & -0.149 & -0.152 & 0.048 & 3.120 & 0.002 \\
\hline SocDemog $\rightarrow$ Decision making & 0.080 & 0.073 & 0.038 & 2.064 & 0.038 \\
\hline Time risk $\rightarrow$ Trust & -0.090 & -0.102 & 0.063 & 1.445 & 0.149 \\
\hline Time risk $\rightarrow$ Decision making & 0.022 & 0.016 & 0.059 & 0.364 & 0.716 \\
\hline
\end{tabular}

( $p$-value $<0.05)$ of the model summary, whose results are presented individually for the constructs of general risk, time risk, financial risk, and psychological risk on purchasers' trust and reliability.

Table 7 shows the final statistical result of the impacts of the risks in question on the trust and decision making variables.

Based on the results shown in Table 7 , the structural model suggests that the correlations and regressions were statistically significant for some relationships $(p$-value $<0.05)$, corroborating Hypotheses $\mathrm{H}_{3}$ (performance risk $\rightarrow$ trust), $\mathrm{H}_{6}$ (general risk $\rightarrow$ decision making, $\mathrm{H}_{8}$ (performance risk $\rightarrow$ decision making), $\mathrm{H}_{11}$ (trust $\rightarrow$ decision making), $\mathrm{H}_{12}$ (SocDemog $\rightarrow$ trust), and $\mathrm{H}_{13}$ (SocDemog $\rightarrow$ decision making). Performance risk was found to have an impact on trust and decision making for online purchases, corroborating Hypotheses 3 and 8, respectively. The only risk that had an impact on trust building and decision making was performance risk, indicating that this risk had a broader impact on the behavior of consumers in the south of Brazil. Therefore, it should be taken into consideration by companies that sell online. General risk only has an impact on decision making regarding online purchases, corroborating Hypothesis 6 . This indicates that general risk has no influence on consumer trust, and the consumer takes only takes this risk into account when deciding to purchase a product or service. Financial risk does not affect either trust or decision making with regard to online purposes, refuting Hypotheses 4 and 9, respectively. Finally, trust affects decision making, corroborating Hypothesis 11 , showing that consumers are not confident that their purchase will bring them benefits and, therefore, they decide not to buy the product.

According to the results presented above, the risks incurred in online purchases that support the model are performance risk of the product and/or service and general risk, which affects decision making but not trust. No signs were found of an impact of psychological and time risk on online purchases, as these risks did not prove to be statistically significant in the proposed model. Therefore, there is evidence that leads to the rejection of Hypotheses $\mathrm{H}_{1}, \mathrm{H}_{2}, \mathrm{H}_{4}, \mathrm{H}_{5}, \mathrm{H}_{7}, \mathrm{H}_{9}$, and $\mathrm{H}_{10}$. In this stage of the study, it was found that the model has convergent validity through all the criteria established by it due to the high factor loadings. Therefore, as shown above, its validity is evident owing to the AVE and CR values and, concomitantly, the factor loadings.

Recent studies have made similar attempts to what is proposed in this study. Swiegers (2018) analyzed South Africa's online consumer behavior. The results indicated that psychological risk
Table 8 Predictive validity $\left(Q^{2}\right)$ and effect size $\left(f^{2}\right)$ values for the constructs of general risk, time risk, performance risk, financial risk, psychological risk, trust, decision making, and demographics.

\begin{tabular}{llll} 
Constructs & $\begin{array}{l}\text { Predictive } \\
\text { validity }\left(\mathbf{Q}^{\mathbf{2}}\right)\end{array}$ & $\begin{array}{l}\text { Effect size (f } \\
\mathbf{2}): \text { trust }\end{array}$ & $\begin{array}{l}\text { Effect size (f } \mathbf{2}^{2} \text { : } \\
\text { decision making }\end{array}$ \\
\hline General risk & - & 0.119 & 0.241 \\
Time risk & - & 0.090 & 0.016 \\
Performance risk & - & 0.256 & 0.338 \\
Financial risk & - & 0.121 & 0.038 \\
Psychological risk & - & 0.036 & 0.091 \\
Trust & 0.177 & - & 0.416 \\
Decision making & 0.447 & - & - \\
Demographics & - & 0.149 & 0.018 \\
Reference values & $Q^{2}>0$ & 0.02 (small); & \\
& & 0.15 (medium) & \\
& & and 0.35 & \\
& & (large) &
\end{tabular}

Source: Adapted from Hair et al. (2014) and data research

and social risk had a significant influence on purchase intention for products, such as clothing and books, which differs from the findings of this study. The data analysis employed by Swiegers (2018) was based on the structural equation model. On the other hand, similarity occurred in financial risk, which had a significant influence on purchase decisions. In Malaysia, the findings of Wahab et al. (2019) highlighted confidence as the most significant aspect of online shopping decision making by looking at the profile of women buying luxury brand products online.

Following the achievement of the confirmatory model for SEM, it was necessary to evaluate the goodness of fit indicators using the blindfolding method. In this context, the values of predictive validity $\left(Q^{2}\right)$, which evaluates how close the model comes to the proposed original, and effect size $\left(f^{2}\right)$, which measures the utility of the construct for the goodness of fit of the model (Hair et al., 2014), were tested. As recommended by Hair et al. (2014), the $Q^{2}$ value should be close to $1\left(Q^{2}=1\right)$, while the $f^{2}$ value should be close to 0.02 . The authors consider an indicator of 0.02 as small, 0.15 as medium, and 0.35 as large. The results are shown in Table 8.

The model presented predictive validity $\left(Q^{2}\right)$ values over zero, indicating that for the dependent variables, the constructs of trust and decision making, the estimated model has good predictive capacity, given that the $Q^{2}$ values were equal to 0.177 and 0.447 , 
respectively. Regarding the effect size in relation to the dependent variable of trust, expressed by $f^{2}$, its individual values indicated that the performance risk construct had the greatest weight in terms of representativeness, given that it had a mean value equal to 0.256 , indicating medium predictive validity, while the time risk construct had a value equal to 0.09 with a low contribution to the formulated model.

Regarding the other dependent variable, decision making, all the estimated values for the $f^{2}$ statistic varied from 0.023 to 0.338 , showing that the items of the analyzed constructs are characterized as useful in the general fit of the formulated model. Considering that part of the study consisted of reporting past consumer experiences in online purchases, it was shown that most decision makers made no mistakes in their purchase operations. Nevertheless, for consumers who had experienced some kind of problem in their purchases, a space was provided to report the problems they faced. Thirty-seven reported that the product they ordered never arrived, 53 complained of the long delay in the delivery of their products and 47 claimed that they received a defective product. Minor problems included lowquality products ( 34 cases), inability to conclude the purchase (26 cases), the product delivered not being the one that was purchased (18 cases) and the price paid being different from the price on the company website (3 cases).

As the demographic variables of gender and age were statistically significant in the structural model, it was decided that it would be interesting to investigate the differentiations of the aforementioned categories in relation to the variables of trust and decision making, evaluating Hypotheses 12 and 13 through multigroup analysis. Thus, the variables were divided into two categories for the respondents' gender and age group with a view to gaining a better standardization of the sample, with non-parametric statistical tests applied later. The results of the multigroup analysis of the demographic variables are shown in Table 9.

Based on the results of the non-parametric Mann-Whitney test on the hypotheses regarding the respondents' gender and age, a statistical significance level of $5 \%$ was adopted, as shown in Table 9. Trust in online purchases in statistical terms differs between the under-29 age group and the higher median age group, corroborating the hypothesis that age groups differ when rejecting the null hypothesis. The same occurs with regard to the decisionmaking construct, rejecting the null hypothesis of equality between the categories under study in terms of risk involving online purchases.

The originality and main contribution of this study lie in the results suggesting that improved measurements related to risks, which confirmed their impact on the consumer's trust and decision making, could be considered a priority by companies. Thus, their focus would be concentrated on aspects related to the performance of products and/or services and general risk. When consumers make a decision, it is natural for them to draw comparisons with their past experiences, as this helps them to create relationships and make decisions regarding a purchase (Costa, 2011). Notably, experiences with a positive outcome help

Table 9 Multigroup analysis of the demographic variables' impact on trust and decision making.

\begin{tabular}{llll} 
Hypotheses & Structural relationship & p-value & Conclusion \\
\hline $\mathrm{H} 12$ & Gender $\rightarrow$ Trust & 0.038 & Corroborated \\
$\mathrm{H} 13$ & Gender $\rightarrow$ Decision making & 0.013 & Corroborated \\
$\mathrm{H} 14$ & Age $\rightarrow$ Trust & 0.021 & Corroborated \\
$\mathrm{H} 15$ & Age $\rightarrow$ Decision making & 0.002 & Corroborated \\
\hline Source: Adapted from Costa (2011) and data research & & \\
\hline
\end{tabular}

to increase trust and provide greater psychological comfort (Costa, 2011).

\section{Final considerations}

The aim of this article was to gauge the impact of different types of perceived risk on trust and decision making in online purchases. The impact of each attribute of risk (e.g. time, performance, financial, psychological, and general) on the consumer's trust and decision to purchase was estimated. To achieve the proposed goal, it was necessary to use and apply a CFA, followed by SEM with the goodness of fit method using PLS to construct the explanatory model. Adjustments were made to the initially proposed model and consequently the AVE and CR values and the factor loadings proved to be acceptable.

The structural equation model representing the impact of perceived risks on trust and decision making regarding online purchases in the region in question is reflected in the performance of the product and/or service and general risk. Performance risk was the only risk with an impact on both constructs of trust and decision making. General risk, formed by a variety of indicators related to the risks, only affected decision making for online purchases.

Trust influenced decision making, showing that consumers are not confident that their purchase will bring them benefits and thus decide not to buy the product. Experience is an element related to risk in the eyes of consumers, and this risk diminishes as the consumer gains similar experiences with more purchases. Thus, performance risk and general risk can be reduced with accumulated successful experiences (Lieberman and Stashevsky, 2002). No signs were identified of the impact of psychological and time risks regarding online purchases, and they did not prove to be significant in the proposed model. This result does not corroborate the findings of Mitchell (1999), who claimed that risks are somehow related, and if a product needs repairs, this will consequently lead to time loss and social loss.

Past experiences with online purchases for most of the consumers in question did not lead to errors in their operations. Therefore, it should be highlighted that successful purchase experiences reduce the perception of risk in online purchases, increasing trust and easing decision making. Consumers who did experience problems in their purchases complained, in descending order, of products never arriving, long delays in delivery or the product being defective. Minor occurrences included impasses regarding the low quality of a product, inability to conclude the purchase, the product not being what was actually purchased and the price being other than the one shown on the company website.

This result shows that both risk perception and past purchase experiences follow the same orientation when their impact on trust and decision making is evaluated. Furthermore, most of the consumers perceived a greater risk related to product performance and general risk. These were also the most recurring risks for individuals who reported problems in past purchase experiences.

It can be concluded that improved measures regarding risks that affected trust and decision making could be considered a priority for companies. Thus, their focus would be extended to aspects related to the performance of products and/or services and general risk. When consumers make a decision, it is natural for them to draw comparisons with their past experiences, helping decision makers to create relationships and make purchase decisions (Costa, 2011). Positive experiences increase trust and lead to greater psychological comfort (Costa, 2011).

To minimize risks in purchases for customers, companies have to show, amidst all the noise, that they honor their commitments and serve consumers as well as they can through one-to-one marketing. Online consumers also have numerous information 
channels to choose from and exclusively choose the company and ensuing consumer journey.

The theoretical contribution of this study lies in gauging perceived risks by adding the latent construct of trust and adapting the scales of the consumer's perceived risk and decision making. The practical contribution is that it highlights the need to reevaluate the strategies of companies that sell products and/or services online in order to reduce these risks and increase consumers' trust when they are deciding whether to make online purchases.

The limitations of the study consist of gauging perceived risk in the south of Brazil. We suggest that studies be conducted comparing regions of Brazil and in other countries, mainly due to the cultural diversity and singular characteristics of different regions of each country. Finally, this study emphasized perceived risk, trust and decision making without considering any specific kind of product. Thus, we suggest that characteristics inherent to each type of product could lead to greater or less perceived risk in the eyes of the decision maker.

\section{Data availability}

All data analyzed or generated are available in the paper.

Received: 14 August 2019; Accepted: 23 December 2019; Published online: 28 January 2020

\section{References}

Audy JLN (2001) Modelo de planejamento estratégico de sistemas de informação: contribuições da aprendizagem organizacional e do processo decisório. Tese de doutorado, Universidade Federal do Rio Grande do Sul, Porto Alegre

Balakrishnan K, Vashishtha R, Verrecchia RE (2019) Foreign competition for shares and the pricing of information asymmetry: evidence from equity market liberalization. J Account Econ 67(1):80-97

Bauer RA (1960) Consumer Behavior as Risk Taking. In: Hancock RS (ed.) Dynamic Marketing for a Changing World, Proceedings of the 43rd. Conference of the American Marketing Association, 389-398

Bertea PE, Zait A (2013) Perceived risk vs. intention to adopt e-commerce: a pilot study of potential moderators. Tržište 25(2):213-229

Brown TA (2006) Confirmatory factor analysis for applied research. The Guilford Press, New York

Cetina I, Munthiu M-C, Radulescu V (2012) Psychological and social factors that influence online consumer behavior. Procedia Soc Behav Sci 62:184-188

Cohen MD, March JG, Olsen JP (1972) A garbage can model of organizational choice. Adm Sci Q 17:1-25

Conrado A (2018) Os 8 Ps do Marketing Digital: o Seu Guia Estratégico de Marketing Digital. Novatec, São Paulo

Costa RS (2007) Processo de compra corporativa de software: um estudo exploratório dos atributos que influenciam na decisão. Dissertação de mestrado, Universidade Federal do Rio Grande do Sul, Porto Alegre

Costa RS (2011) A influência da confiança do decisor no risco percebido e no processo decisório. Tese de doutorado, Universidade Federal do Rio Grande do Sul, Porto Alegre

Cunningham LF, Gerlach JH, Harper MD, Young CE (2005) Perceived risk and the consumer buying process: internet airline reservations. Int J Serv Ind Manag 16(4):357-372

Cunningham SM (1967) The major dimensions of perceived risk. In: Cox DF (Ed.) Risk-taking and information-handling in consumer behavior. Harvard University Press, Boston

Das TK, Teng B (2004) The risk-based view of trust: a conceptual framework. J Bus Psychol 19(1):85-116

Dowling GR (1986) Perceived risk: the concept and its measurement. Psychol Mark 3:193-210

Dowling GR, Staelin R (1994) A model of perceived risk and risk-handling activities. J Consum Res 21:119-134

Driediger F, Bhatiasevi V (2019) Online grocery shopping in Thailand: consumer acceptance and usage behavior. J Retail Consum Serv 48:224-237

Faulds DJ, Mangold WG, Raju PS, Valsalan S (2018) The mobile shopping revolution: redefining the consumer decision process. Bus Horiz 61:323-338

Festinger L (1957) A theory of cognitive dissonance. Stanford University Press, Stanford
Fornell C, Larcker DF (1981) Evaluating structural equation models with unobservable variables and measurement error. J Mark Res 18(1):39-50

Hagberg J, Jonsson A, Egels-Zandén N (2017) Retail digitalization: implications for physical stores. J Retail Consum Ser 39:264-269

Hair JF, Black WC, Babin BJ, Anderson RE, Tatham RL (2009) Análise multivariada de dados. Bookman, Porto Alegre

Hair JF, Sarstedt M, Hopkin L, Kuppelwieser VG (2014) Partial least square structural equation modeling (PLS-SEM): an emerging tool in business research. Eur Bus Rev 26(2):106-121

Hänninen M, Mitronen L, Kwan SK (2019) Multi-sided marketplaces and the transformation of retail: a service systems perspective. J Retail Consum Serv 49:380-388

Henseler J, Ringle CM, Sinkovics RR (2009) The use of partial least squares path modeling in international marketing. Adv Int Mark 20:277-319

Heylighen F, Lenartowicz M (2017) The Global Brain as a model of the future information society: an introduction to the special issue. Technol Forecast Soc Change 114:1-6

Hong Z, Yi L (2012) Research on the influence of perceived risk in consumer online purchasing decision. Phys Procedia 24(Part B):1304-1310

Hor-Meyll LF (2004) Construção de uma escala para mensurar o risco percebido na compra online de um serviço hoteleiro. Anais do Encontro da Associação Nacional dos Programas de Pós-Graduação em Administração, Curitiba

Jacoby J, Leon BK (1972) The Components of Perceived Risk In: Venkatesan M (ed.) SV - Proceedings of the Third Annual Conference of the Association for Consumer Research. Association for Consumer Research, Chicago, IL, 382-393

Karahanna E, Straub DW, Chervany NL (1999) Information technology adoption across time: a cross-sectional comparison of pre-adoption and post-adoption beliefs. Manag Inf Syst Q 23(2):183-213

Keng CJ, Liao TH (2009) Consequences of post purchase dissonance: The mediating role of an external information search. Soc Behav Personality: Int J 37 (10): $1327-1340$

Khalil S, Mansi S, Mazboudi M, Zhang AJ (2019) Information asymmetry and the wealth appropriation effect in the bond market: evidence from late disclosures. J Bus Res 95:49-61

Kim DJ, Ferrin DL, Rao HR (2008) A trust-based consumer decision-making model in electronic commerce: the role of trust, perceived risk, and their antecedents. Decis Support Syst 44:544-564

Kim Y, Krishnan R (2015) On product-level uncertainty and online purchase behavior: an empirical analysis. Manag Sci 61(10):2281-2547

Korgaonkar P, Wolin L (1999) A multivariate analysis of Web usage. J Advert Res 39(2):53-68

Liao T-H (2017) Online shopping post-payment dissonance: dissonance reduction strategy using online consumer social experiences. Int J Inf Manag 37 (6):520-538

Liebermann Y, Stashevsky S (2002) Perceived risks as barriers to Internet and ecommerce usage. Qual Mark Res 5(4):291-300

Lin WB (2008) Investigation on the model of consumers perceived risk: integrated viewpoint. Expert Syst Appl 34:977-988

Loomes G, Mehta J (2007) The sensitivity of subjective probability to time and elicitation method. J Risk Uncertain 34:201-216

Maceira M, Carvalho F, Lima V (2011) Fatores demográficos na percepção de risco de compra pela internet. Rev Port Bras Gest 1:92-100

Machado A (2014) Estudo da EMC prevê que volume de dados virtuais armazenados será seis vezes maior em 2020. Tecnologia. http://oglobo.globo.com/sociedade/ tecnologia/estudo-da-emc-preve-que-volume-de-dados-virtuais-armazenadossera-seis-vezes-maior-em-2020-12147682. Accessed 11 May 2019

Mackenzie SB, Podsakoff PM, Jarvis CB (2005) The problem of measurement model misspecification in behavioral and organizational research and some recommended solutions. J Appl Psychol 90(4):710-730

Malhotra NK (2001) Pesquisa de marketing: uma orientação aplicada. Bookman, Porto Alegre

Meertens MR, Lion R (2008) Measuring an individual's tendency to take risks: the risk propensity scale. J Appl Soc Psychol 38(6):1520-1526

Miller SJ, Hickson DI, Wilson DC (2004) A tomada de decisão nas organizações. In: Clegg SR, Hardy C, Nord W (eds) (Orgs.) Handbook de Estudos Organizacionais, vol. 3. Atlas, São Paulo

Mitchell VW (1990) Industrial risk in the purchase of microcomputers. Eur J Mark 24(5):7-19. https://doi.org/10.1108/03090569010003617

Mitchell VW (1991) An empirical investigation of perceived risk in the purchase of planning consultancy by local authorities. Unpublished PhD thesis, UMIST, Manchester

Mitchell VW (1995) Organisational perceived risk: a literature review. Br Manag J 6 (2):115-33

Mitchell VW (1999) Consumer perceived risk: conceptualisations and models. Eur J Mark 33(1):163-195

Morelatto SA (2010) Modelos de regressão PLS com erros heterocedásticos. Dissertação de mestrado, Universidade de São Carlos, São Carlos, SP

Morgan RM, Hunt SD (1995) The commitment-trust theory of relationship marketing. J Mark 58:20-38 
Novak TP, Hoffman DL, Yung Y-F (2000) Measuring the customer experience in online environments: a structural modeling approach. Mark Sci 19 (1):22-42

Petit O, Velasco C, Spence C (2019) Digital sensory marketing: integrating new technologies into multisensory online experience. J Interact Mark 45:42-61

Raluca MU (2018) The power of rankings: quantifying the effect of rankings on online consumer search and purchase decisions. Market Sci Adv (online publication 29 Jun 2018) https://doi.org/10.1287/mksc.2017.1072

Ringle CM, Wende S, Becker J-M (2015) SmartPLS 3. SmartPLS GmbH, Boenningstedt

Roselius T (1971) Consumer ranking of risk reduction methods. J Mark 35 (1):56-61

Swiegers L (2018) Perceived risk barriers to online shopping: experiences of technologically enabled generation y consumers. Thesis (Master of Commerce), Faculty of Economic and Management Sciences at Stellenbosch University

Urbina S (2007) Fundamentos de testagem psicológica (C. Dornelles, Trad.). Artmed, Porto Alegre, (Original publicado em 2004)

Vos A, Marinagi C, Trivellas P, Eberhagen N, Giannakopoulos G (2014) Risk reduction strategies in online shopping: E-trust perspective. Procedia-Soc Behav Sci 147:418-423

Wahab FZA, Mokhtar NF, Set K (2019) Investigating the factors of trust and risk on career women in luxury brand purchasing intention through online in Malaysia. Int J Account Financ Bus 4(19):108-122

Weick KE (1995) Sensemaking in organizations. Sage, London

Xu Y, Koivumäki T (2019) Digital business model effectuation: an agile approach. Comput Hum Behav 95:307-314

Zhuang H, Leszczyc PTLP, Lin Y (2018) Why is price dispersion higher online than offline? The impact of retailer type and shopping risk on price dispersion. J Retail 94(2):136-153

\section{Competing interests}

The authors declare no competing interests.

\section{Additional information}

Correspondence and requests for materials should be addressed to C.P.d.V.

Reprints and permission information is available at http://www.nature.com/reprints

Publisher's note Springer Nature remains neutral with regard to jurisdictional claims in published maps and institutional affiliations.

\section{(c) (1)}

Open Access This article is licensed under a Creative Commons Attribution 4.0 International License, which permits use, sharing, adaptation, distribution and reproduction in any medium or format, as long as you give appropriate credit to the original author(s) and the source, provide a link to the Creative Commons license, and indicate if changes were made. The images or other third party material in this article are included in the article's Creative Commons license, unless indicated otherwise in a credit line to the material. If material is not included in the article's Creative Commons license and your intended use is not permitted by statutory regulation or exceeds the permitted use, you will need to obtain permission directly from the copyright holder. To view a copy of this license, visit http://creativecommons.org/ licenses/by/4.0/

(C) The Author(s) 2020 